\title{
Prevalence of Subclinical Hypothyroidism in Non- Pregnant Females of Childbearing Age Coming to North Bengal Medical College Out Patient Department
}

\author{
Arup Kumar Banerjee ${ }^{1}$, Mohammad Selim² \\ ${ }^{1}$ Department of Biochemistry, North Bengal Medical College, Darjeeling, West Bengal, India. \\ ${ }^{2}$ Department of Physiology, North Bengal Medical College, Darjeeling, West Bengal, India.
}

\section{ABSTRACT}

\section{BACKGROUND}

Hypothyroidism is widespread in sub-Himalayan region and is particularly prevalent in females of reproductive age group. Since the signs and symptoms of subclinical hypothyroidism are often overlooked by the patients themselves, the diagnosis gets often delayed. In this study, we tried to estimate the prevalence of subclinical hypothyroidism in reproductive age group female population coming to the outpatient department of a government hospital in North Bengal.

\section{METHODS}

All the non-pregnant women attending the blood collection center of the Department of Biochemistry, North Bengal Medical College and Hospital, were enrolled in the study after institutional ethics approval. Women of age ranging from 10 years to 65 years were included in the study to compare the possible difference of prevalence existing between different age groups. The women with known thyroid disease and other autoimmune disorders were excluded from the study. Fasting blood samples of study participants were analysed for thyroid hormone profile. In addition, all study participants were tested for Hb\%, FBS, LFT, KFT, and lipid profile. Microsoft Excel and SPSS version 22 was used for data analysis.

\section{RESULTS}

Subclinical hypothyroidism prevalence was found to be $13.4 \%$ in reproductive age group women. The prevalence is not different from the general population as such. The prevalence of overt hypothyroidism was also similar in overall population and reproductive age group females. The prevalence of subclinical hypothyroidism was found to be higher in females of age group 10-19 years $(16.7 \%)$ and 60-65 years $(16.2 \%)$ than that seen in reproductive age group females.

\section{CONCLUSIONS}

The prevalence of subclinical hypothyroidism is quiet high in female population and the result in this study goes parallel to the findings of other studies. In this study, subclinical hypothyroidism is found to be more prevalent in both higher and lower age group females compared to the females of reproductive age group.

\section{KEY WORDS}

Hypothyroidism, Sub Clinical Hypothyroidism, Prevalence, Sub-Himalayan Region
Corresponding Author: Dr. Arup Kumar Banerjee, Assistant Professor, Department of Biochemistry, North Bengal Medical College, Darjeeling-734102, West Bengal, India. E-mail: dr.arup.banerjee@gmail.com

DOI: $10.14260 / \mathrm{jemds} / 2020 / 401$

Financial or Other Competing Interests: None.

How to Cite This Article: Banerjee AK, Selim M. Prevalence of subclinical hypothyroidism in nonpregnant females of childbearing age coming to north Bengal medical college out patient department. J. Evolution Med. Dent. Sci. 2020;9(25):1838-1841, DOI: $10.14260 /$ jemds $/ 2020 / 401$

Submission 29-03-2020,

Peer Review 23-05-2020,

Acceptance 29-05-2020,

Published 22-06-2020.

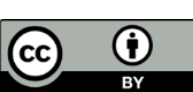




\section{BACKGROUND}

Hypothyroidism is a common disease condition in sub Himalayan region and the prevalence of hypothyroidism is greater in females.(1) Hypothyroidism in both clinical and subclinical form has definitive adverse outcome both in pregnancy and in the later life of the child borne.(2),(3) During pregnancy both Iodine requirement and thyroid hormone production increases approximately by $50 \%(4)$ and hypothyroidism during pregnancy increases the risk of abortion, premature delivery, stillbirth and birth of congenitally defective babies.(1) Children born to hypothyroid mothers have far-reaching effect on future intellectual development,(5) attention deficit and hyperactivity syndrome have been reported in children born to hypothyroid mothers.(6),(7) Not only that hypothyroidism during fetal and post-natal life also interferes with normal development and maturation of Central Nervous System. (8),(9)

So, it is important to diagnose hypothyroidism in the females of childbearing age group and treat them. Hypothyroidism is a widespread condition and since in its subclinical form its nonspecific symptoms may be overlooked by the patients,(10),(11) the diagnosis of subclinical hypothyroidism itself could be a challenge for the clinicians. Not only due to the inconspicuous signs and symptoms of hypothyroidism, it is difficult to diagnose during pregnancy since the signs can be similar to those of pregnancy.(1)

Here we tried to find out the prevalence of subclinical hypothyroidism in the child bearing age group female population to understand the actual burden of a potentially undiagnosed condition which has immense effect on the health and wellbeing of the women of child bearing age group and also to find how the prevalence differs if estimated in general female population.

\section{METHODS}

This is an institution based cross sectional study. It was conducted in North Bengal Medical College and Hospital in the Department of Biochemistry in collaboration of the Department of Physiology after clearance of the Ethical committee of the Institution. We took one-year time period from January 2019 to January 2020 to conduct the study. Patients coming to the Laboratory for testing blood for other clinical conditions who fulfilled the inclusion and exclusion criteria and signed the consent form had been included in the study population. Female of age 10 to 65 were included in the study. For minor age group females, the attending parent(s) were asked to sign the consent form. Subjects with known chronic disease condition like diabetes mellitus, hypertension, known hypo or hyperthyroidism, any autoimmune disorders, were excluded from the study along with pregnant females and persons with acute illness. Smoking and alcohol users had also been excluded.

A detailed history was taken using a predesigned format and necessary clinical examinations were conducted. Blood samples were collected in the departmental blood collection center for hormone analysis. From each of the patients $6 \mathrm{ml}$ of blood was drawn aseptically using proper technique and 2 $\mathrm{ml}$ of blood was stored in EDTA vial and $4 \mathrm{ml}$ in clotted vial. Serum Bilirubin (Direct and Total), AST, ALT, Urea, Creatinine, Lipid profile and $\mathrm{Hb} \%$ were estimated for each of the patients along with serum TSH and fT4. Serum Bilirubin, AST, ALT, Urea, Creatinine, Lipid profile estimation was done in Erba EM 360 autoanalyzer machine and $\mathrm{Hb} \%$ was measured in Sysmax XS800i 5-part haematology analyser. Serum TSH and fT4 was measured in Advia Centaur XL Siemens immunoassay machine using dedicated kit for them. Diagnostic criteria for hypothyroidism were set as follows. Normal range of TSH was taken as $0.34-4.5 \mathrm{mIU} / \mathrm{ml}$ and Clinical or overt hypothyroids are those who has TSH $\geq 10$ $\mathrm{mIU} / \mathrm{ml}$ with symptoms like lethargy, weight gain, menstrual abnormalities, hair loss etc. Subclinical hypothyroids as TSH 4.51-10.0 mIU/l with no or mild clinical sign and symptoms of hypothyroidism. The data were entered initially in Excel sheet and the statistical analysis was done SPSS for Windows version 22 .

\section{RESULTS}

The baseline characteristics are given in table no 1 . The population has a mean age of 35.99 years. Mean blood pressure (both systolic and diastolic) was normal in the study population. No obvious renal and hepatic derangement was there as evidenced by normal mean value of all the renal and hepatic parameters. Normal mean values of lipid profile parameters signify the absence of any obvious dyslipidaemias. Mean values of serum TSH and FT4 has also been shown in the table.

\begin{tabular}{|ccc|}
\hline Parameters & Mean & SD \\
Age (Years) & 35.99 & 13.07 \\
Pulse & 72 & 9.08 \\
Systolic blood pressure (mm Hg) & 121 & 13.28 \\
Diastolic blood pressure (mm HG) & 79 & 7.17 \\
Hb\% & 11 & 1.06 \\
Urea (mg/dL) & 28 & 7.43 \\
Creatinine(mg/dL) & 0.8 & .21 \\
Total Bilirubin(mg/dL) & 0.6 & .03 \\
Direct Bilirubin(mg/dL) & 0.1 & .01 \\
AST (U/l) & 30 & 14.37 \\
ALT (U/l) & 32 & 12.98 \\
Total cholesterol(mg/dL) & 156 & 33.76 \\
HDL Cholesterol(mg/dL) & 56 & 17.93 \\
LDL Cholesterol(mg/dL) & 94 & 23.56 \\
TSH (mIU/l) & 5.7 & 17.42 \\
fT4 (ng/dl) & 1.29 & 0.87 \\
\hline Table 1. Baseline Characteristics of the Study Population \\
\hline
\end{tabular}

The thyroid status of different group of population is shown in Table 2. The reproductive age group population has been grouped out of the total population and statistical analysis had been done in both populations. The total number of persons included (only females) was 737 and out of them 553 were in reproductive age group. The table shows the mean values of TSH and FT4 and also the percent of clinical and subclinical hypothyroid patients present in total population and in reproductive age group population separately. 


\begin{tabular}{|ccc|}
\hline & Total Population & Reproductive Age Group \\
Number & 737 & 553 \\
TSH (Mean \pm 2 SD) & $5.7( \pm 17.42)$ & $5.27( \pm 15.81)$ \\
fT4 (Mean \pm 2 SD) & $1.29( \pm 0.87)$ & $1.3( \pm 0.96)$ \\
\% Euthyroid & 79.2 & 79.7 \\
\%Subclinical Hypothyroidism & 13.4 & 13.4 \\
\%Clinical Hypothyroidism & 7.4 & 6.9 \\
\hline \multicolumn{2}{|c|}{ Table 2. Thyroid Status in the Population } \\
\hline
\end{tabular}

Table 3. Shows the age wise prevalence of subclinical and clinical hypothyroidism in the population. We divided the whole population into 6 groups as show in the table and calculated the prevalence of hypothyroidism in each of the groups. Figure 1 shows age group wise distribution of Subclinical hypothyroidism.

\begin{tabular}{|ccccc|}
\hline $\begin{array}{c}\text { Age } \\
\text { Group } \\
\text { (Years) }\end{array}$ & No. & $\begin{array}{c}\text { Percentage in } \\
\text { Total } \\
\text { Population }\end{array}$ & $\begin{array}{c}\text { Prevalence of } \\
\text { Subclinical } \\
\text { Hypothyroidism }\end{array}$ & $\begin{array}{c}\text { Prevalence of } \\
\text { Clinical } \\
\text { Hypothyroidism }\end{array}$ \\
$20-19$ & 72 & 9.8 & 16.7 & 6.9 \\
$30-39$ & 180 & 24.4 & 13.9 & 7.8 \\
$40-49$ & 187 & 25.4 & 12.3 & 4.8 \\
$50-59$ & 87 & 22.7 & 13.2 & 9.6 \\
$60-69$ & 37 & 11.8 & 10.3 & 9.2 \\
\hline \multicolumn{5}{c}{ Table 3. Age Wise Prevalence of Hypothyroidism } \\
\hline
\end{tabular}

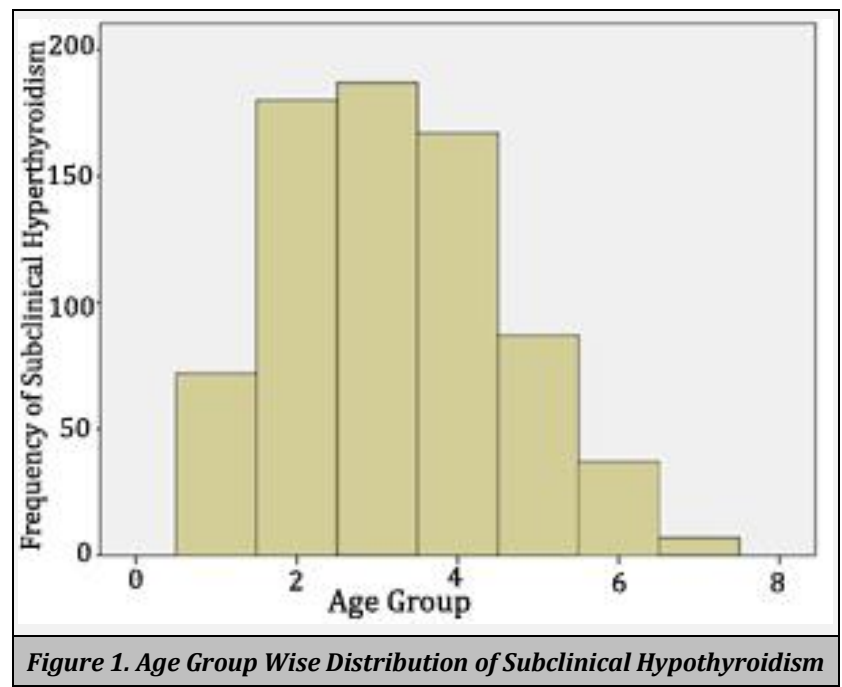

\section{DISCUSSION}

Thyroid disorder is one of the most common endocrine disorders in India. Subhimalayan region is one well known area where iodine deficiency disorder is very much prevalent despite the coverage of National Iodine Deficiency Disease Control Program (NIDDCP).

Normal Blood pressure, $\mathrm{Hb} \%$, renal parameters, liver function parameters and Lipid profile parameters signify the absence of any associated significant illness. The mean TSH value was found to be $5.7 \pm 17.42$ in overall population and $5.27 \pm 15.81$ in reproductive age group females which is statistically non-significant $(p>5)$. Similarly, the difference between the mean value of FT4 between overall population $(1.29 \pm 0.87)$ and reproductive age group females $(1.3 \pm 0.96)$ was found to be non-significant $(p>5)$. In both the groups most of the people was euthyroid $(79.2 \%$ in total population vs. $79.7 \%$ in reproductive age group females) and the difference of prevalence of subclinical and overt hypothyroidism is not much, they are statistically almost similar. The prevalence of subclinical hypothyroidism was found to be identical in both the groups as $13.4 \%$ and the prevalence of overt hypothyroidism was found to be $7.4 \%$ in total population whereas is was $6.9 \%$ in the reproductive age group people. The findings are similar to that of other studies done by Archana J. Dhok and colleagues(12) where they detected a prevalence rate of subclinical hypothyroidism as $14.8 \%$. Abraham et al.(13) had detected a prevalence rate of 9.5\% and Skaria et al(14) had a result of $12.6 \%$.

Another important finding is the higher prevalence (16.7\%) of subclinical hypothyroidism among the females of age group 10-19 years and the next highest was the prevalence in age group 60-69 years (16.2\%) and both are higher than the prevalence of subclinical hypothyroidism in reproductive age group females (13.4\%).

Similar finding was seen in a study done by Harish Kumar et al where the found a prevalence of $13.2 \%$ of subclinical hypothyroidism in females with age group of 60-71 years which is lower than what we found in this study.

\section{CONCLUSIONS}

Concomitant estimation of Anti TPO antibody in the population would have thrown some more light on this matter but because of limited funds we could not do it. In the next phase of the study there lies a scope for that Nevertheless from this study we can come to a conclusion that the estimated prevalence of subclinical hypothyroidism is quite high in the population and not only the reproductive age group females, the pubertal age group females as well as the females of higher age group have even greater chance of having subclinical hypothyroidism and clinicians should be vigilant enough to diagnose it.

\section{REFERENCES}

[1] Ray A, Biswas U, Mukherjee A, et al. Assessment of iodine and non-iodine deficiency hypothyroidism in women of reproductive ages in the sub-Himalayan plains of West Bengal. Indian J Physiol Pharmacol 2009; 53(4):359-64.

[2] Dhanwal DK, Prasad S, Agarwal AK, et al. High prevalence of subclinical hypothyroidism during first trimester of pregnancy in North India. Indian J Endocrinol Metab 2013; 17(2):281-4.

[3] Tudosa R, Vertej P, Horhoianu I, et al. Maternal and fetal complications of the hypothyroidism-related pregnancy. Maedica (Buchar) 2010; 5(2):116-23.

[4] Glinoer D. The regulation of thyroid function in pregnancy: pathways of endocrine adaptation from physiology to pathology. Endocr Rev 1997; 18(3):40433.

[5] Stagnaro-Green A, Abalovich M, Alexander E, et al. Guidelines of the American Thyroid Association for the diagnosis and management of thyroid disease during pregnancy and postpartum. Thyroid 2011; 21(10):1081125.

[6] Ghassabian A, Bongers-Schokking JJ, de Rijke YB, et al. Maternal thyroid autoimmunity during pregnancy and the risk of attention deficit/hyperactivity problems in 
children. The Generation R Study. Thyroid 2012; 22(2):178-86.

[7] Männistö T, Vääräsmäki $M$, Pouta $A$, et al. Perinatal outcome of children born to mothers with thyroid dysfunction or antibodies: a prospective populationbased cohort study. J Clin Endocrinol Metab 2009; 94(3):772-9.

[8] Larsen PR. Thyroid hormone concentrations. In: Ingbar SH, Braverman LE, Eds. The Thyroid. $5^{\text {th }}$ edn. Philadelphia: Lippincott Co, 1986: p. 479-501.

[9] De Escobar MG, Del Rey EF, Ruiz-Marcos A. Thyroid hormone and the developing brain. In: Dussault JH, Walker P, eds. Congenital Hypothyroidism. New York: Marcel Decker Inc., 1983: p. 85-126.

[10] Bemben DA, Hamm RM, Morgan L, et al. Thyroid disease in the elderly. Part 2. Predictability of subclinical hypothyroidism. The Journal of Family Practice 1994; 38(6):583-8.

[11] Ahmad N, Panthari M, Gupta A, et al. Prevalence of hypothyroidism among patients of Meerut, Uttar Pradesh: a hospital based study. International Journal of Medical Science and Public Health 2013; 2(3):539-42.

[12] Dhok AJ, Adole PS, Puppalwar PV, et al. Status of Thyroid disorders at Acharya Vinobha Bhave Rural Hospital, Sawangi (Meghe), Wardha, India. Thyroid Research J and Practice 2015; 12(2):62-6.

[13] Abraham R, Murugan SV, Pukazhvanthen P, et al. Thyroid disorders in women of Puducherry. Indian J Clin Biochem 2009; 24(1):52-9.

[14] Skaria LK, Sarkar PD, Agnihitram G, et al. Thyroid dysfunction in tribal women of Bastar region of Chattisgharh, India. Thyroid Sci 2011;6(6):1-5. 